\title{
Congenital disorders of glycosylation. Part I. Defects of protein $\mathrm{N}$-glycosylation
}

\author{
Bogdan Cylwik ${ }^{\bowtie}$, Marcin Naklicki, Lech Chrostek and Ewa Gruszewska \\ Department of Biochemical Diagnostics, Medical University of Bialystok, Białystok, Poland
}

\begin{abstract}
Glycosylation is the most common chemical process of protein modification and occurs in every living cell. Disturbances of this process may be either congenital or acquired. Congenital disorders of glycosylation (CDG) are a rapidly growing disease family, with about $\mathbf{5 0}$ disorders reported since its first clinical description in 1980. Most of the human diseases have been discovered recently. CDG result from defects in the synthesis of the $\mathrm{N}$ - and $\mathrm{O}$ glycans moiety of glycoproteins, and in the attachment to the polypeptide chain of proteins. These defects have been found in the activation, presentation, and transport of sugar precursors, in the enzymes responsible for glycosylation, and in proteins that control the traffic of component. There are two main types of protein glycosylation: N-glycosylation and O-glycosylation. Most diseases are due to defects in the $\mathrm{N}$-glycosylation pathway. For the sake of convenience, CDG were divided into 2 types, type I and II. CDG can affect nearly all organs and systems. The considerable variability of clinical features makes it difficult to recognize patients with CDG. Diagnosis can be made on the basis of abnormal glycosylation display. In this paper, an overview of CDG with a new nomenclature limited to the group of protein $\mathrm{N}$ glycosylation disorders, clinical phenotype and diagnostic approach, have been presented. The location, reasons for defects, and the number of cases have been also described. This publication aims to draw attention to the possibility of occurrence of CDG in each multisystem disorder with an unknown origin.
\end{abstract}

Key words: N-glycosylation, genetic defects, diagnostics

Received: 17 February, 2013; revised: 15 April, 2013; accepted: 23 May, 2013; available o-line: 31 May, 2013

\section{INTRODUCTION}

Glycosylation is the most common modification of chemical proteins that takes place in every human cell (Freeze \& Schachter, 2009). This process involves a covalent attachment of one or several carbohydrate chains to the amide group of the asparagine ( $\mathrm{N}$-glycoprotein), or rarely to the hydroxyl group of serine or threonine $(\mathrm{O}-$ glycoprotein) of the protein polypeptide chain (Freeze \& Schachter, 2009). The N-glycosylation pathway in the cytoplasm, endoplasmic reticulum (ER), and Golgi apparatus has four main steps: biosynthesis of lipid-linked oligosaccharide (LLO), en block transfer of carbohydrate chain from dolichol phosphate to the nascent polypeptide chain of protein, remodeling of protein-bound N-glycan in the ER (basic glycosylation), and further modification of $\mathrm{N}$ glycan in Golgi (final glycosylation) (Freeze \& Schachter, 2009). The full N-glycosylation pathway is a site-specific process consisting of at least 40 steps, and depends on a number of enzymes (especially glycosyltransferases) and some transport proteins. The biosynthesis of all $\mathrm{N}$-glycans occurs in a uniform manner. A complete absence of $\mathrm{N}$ glycans is lethal. The carbohydrate component $(\mathrm{N}$ - or Oglycan) of glycoproteins constitutes at least $20 \%$ (sometimes only $1 \%$ ), and in some cases reaches even up to $80 \%$ of the molecular weight. The glycans usually consist of hexoses and their derivatives (most often mannose, galactose, $\mathrm{N}$-acetylglucosoamine, $\mathrm{N}$-acetylgalactosoamine) and various sialic acids (Freeze \& Schachter, 2009). Sialic acids are typically located at the terminal end of glycan structures. In plasma glycoproteins, sialic acids constitute from 3 to $7 \%$ of the glycoprotein content, however in breast milk or mucoses and epithelia about $25 \%$. In turn, the glycoproteins of leukocyte membrane can contain up to $50 \%$ of sialic acids (Sillanaukee et al., 1999). Most of the blood plasma, tissue fluids, mucus, and membrane proteins are glycosylated.

Correct glycosylation is essential for obtaining and supporting a normal biological activity of proteins, and its impairment leads to the synthesis of glycoproteins with reduced or lost function. Glycosylation is the primary cause of microheterogeneity in proteins. It means that a particular glycoprotein may exist in many molecular variants that differ in the structure of carbohydrates (glycoforms). In healthy people, glycoproteins have a normal protein isoform pattern that may change in a characteristic manner in many diseases. Generally, disturbances of glycosylation may be either congenital or acquired. Congenital disorders of glycosylation were originally called carbohydrate-deficient glycoprotein syndromes (CDGS) (Niehues et al., 1998; Carchon et al., 1999; Korner et al., 1999) and after year 2000 were renamed on congenital disorders of glycosylation (CDG) (Participants, 2000). They result from genetic defects leading to the deficiency or loss of enzyme activity involved in glycan synthesis and processing, or to deficiency of specific transporters (Freeze \& Schachter, 2009). Genetic defects cause severe multiorgan and multisystem disorders that are manifested as early as in the first months of life. About $20 \%$ of patients do not live past their fifth year of life. Broad clinical features involve many system organs, but specifically relate to the development of certain regions of the brain and functions of the gastrointestinal, hepatic,

e-mail: cylwikb@umb.edu.pl

Abbreviations: CDG, congenital disorders of glycosylation; DolP, dolichol phosphate; Dol-P-Glc, dolichol-P-glucose; Dol-P-Man, dolichol-P-mannose; ER, endoplasmic reticulum; Fru-6-P, fructose6-phosphate; GDP-Man, guanosine diphosphate-mannose; IEF, isoelectrofocusing; LLO, lipid-linked oligosaccharide; Man-1-P, mannose-1-phosphate; Man-6-P, mannose-6-phosphate; OST, oligosaccharyltransferase complex; PMI, phosphomannose isomerase; PMM2, phosphomannomutase II; Tf, transferrin; TIEF, transferrin isoelectrofocusing 
visual, and immune systems (Freeze \& Schachter, 2009). More than 30 years have passed (Jaeken et al., 1980) since the first clinical description of the defect of protein glycosylation by Jaeken et al. (in 1980). Since that time 45 CDG have been identified (Theodore \& Morava, 2011). Congenital disorders of glycosylation are a rapidly growing disease family (in years 2003-2010 the number rose from 12 to 45), and knowing that about 250 genes are considered to be involved in glycosylation, it is believed that many diseases will be identified in the future (Jaeken, 2010; Jaeken, 2011). In 2009, a novel nomenclature for all types of CDG was proposed, which combines the name of the defective gene followed by a common ,-CDG” ending (e.g. PMM2-CDG instead CDG Ia) (Jaeken et al., 2009).

In this paper, an overview of congenital disorders of N-glycosylation pathway with a novel nomenclature, classification, location, and reasons for defects, clinical phenotype, and diagnostic approach, have been presented. The paper aims to increase access to scientific information about genetic diseases, especially in cases with an unknown origin, and to facilitate their diagnosis.

\section{NOVEL CLASSIFICATION OF CONGENITAL DISORDERS OF GLYCOSYLATION}

In 2009, a novel classification of CDG was proposed, according to the type of glycosylation defect that distinguishes 4 categories of disorders:

- Defects of protein N-glycosylation (17 diseases)

- Defects of protein O-glycosylation (8 diseases)

- Defects of lipid glycosylation and of glycosylphosphatidylinositol (GPI) anchor glycosylation (3 diseases)

- Defects in multiple glycosylation pathways and in other pathways (17 diseases) (Jaeken, 2011).

Due to the fact that the most frequently identified types of CDG are associated with disrupted or defective N-glycosylation pathway, this article concerns only this category of diseases.

\section{DIVISION AND CHARACTERIZATION OF CDG RELATED TO THE IMPAIRED PATHWAY OF N-GLYCOSYLATION}

For the sake of convenience, CDG defects related to the impaired pathway of $\mathrm{N}$-glycosylation (17 diseases are known) are divided into two types, I and II:

CDG type I involves disrupted synthesis of the lipid linked oligosaccharide precursor (LLO) and its transfer to polypeptide chain of protein:

- 15 subtypes (according to the new nomenclature): PMM2-CDG (CDG-Ia), PMI-CDG (CDG-Ib), ALG6CDG (CDG-Ic), ALG3-CDG (CDG-Id), ALG12-CDG (CDG-Ig), ALG8-CDG (CDG-Ih), ALG2-CDG (CDGIi), DPAGT1-CDG (CDG-Ij), ALG1-CDG (CDG-Ik), ALG9-CDG (CDG-Il), RFT1-CDG (CDG-ln), ALG11CDG (CDG-Ip), DDOST-CDG (CDG-Ir): TUSC3CDG, MAGT1-CDG)

CDG type II involves malfunctioning trimming/processing of the protein-bound oligosaccharide chain:

- 2 subtypes: MGAT2-CDG (CDG-IIa), GCS1CDG (CDG-IIb).

\section{PMI-CDG (CDG-Ib): deficiency of phosphomannose isomerase (EC 5.3.1.8)}

Phosphomannose isomerase occurs in the cytoplasm and catalyzes the conversion of fructose-6-phosphate (Fru-6-P) to the mannose-6-phosphate (Man-6-P), which is converted to the mannose-1-phosphate (Man-1-P). Man-1-P serves as a substrate in the nucleotide sugar GDP-Man, which is crucial for proper N-glycosylation. Man-1-P serves as a donor substrate for the formation of dolichol-P-mannose (Dol-P-Man) and the initial Man ${ }_{5}$ GlcNAc $c_{2}$-P-Dol structure (Fig. 1a) (Freeze \& Schachter, 2009). Mannose is one of the basic monosaccharides involved in the synthesis of fourteen-sugar lipid-linked oligosaccharide (LLO) precursor ( $\left.\mathrm{Glc}_{3} \mathrm{Man}_{9} \mathrm{GlcNAc}_{2}-\mathrm{PP}-\mathrm{Dol}\right)$. PMI-CDG results from mutations in the PMI gene that leads to the deficiency of phosphomannose isomerase (Table 1) (Niehues et al., 1998). Reduced phosphomannose isomerase activity decreases the Man-6-P pool, what causes the glycosylated proteins to be devoid of entire sugar chains and the Asn-X-Ser or Asn-X-Thr Nglycosylation sequons of polypeptide chain to be unoccupied.

The clinical phenotype of PMI-CDG was first described in 1986 in 4 children whose parents came from Canada (Pelletier et al., 1986). Until now, 20 patients affected by this defect are known (Niehues et al., 1998). In contrast to PMM2-CDG, these patients do not have psychomotor retardation, but mainly hepatic-intestinal symptoms (severe vomiting, diarrhea, gastrointestinal bleeding, and protein-losing enteropathy) are present (Jaeken, 2010; Freeze \& Westphal, 2001). Coagulation disturbances and hypoglycemia have been found in some patients (Freeze \& Westphal, 2001; Jaeken, 2010). It is the only one of all CDG disorders that can be treated effectively with oral mannose supplementation (Marquardt \& Denecke, 2003; de Lonlay \& Seta, 2009). The effectiveness of mannose therapy is possible due to the fact that these patients have a normal activity of hexokinase, which provides an alternative pathway (phosphorylation) for the synthesis of mannose-6-phosphate (Man6-P) from mannose (Freeze \& Schachter, 2009). Serum transferrin isoform profile showed a pattern consistent with CDG type I (the increase of asialo- and disialo, and the decrease of tetrasialotransferrin) (Jaeken, 2010). The diagnosis of this defect is confirmed by a significant deficiency of phosphomannose isomerase in leukocytes or fibroblasts (with activity decreased to approximately $7 \%$ of the values in healthy subjects) (Niehues et al., 1998). Laboratory studies indicate a decrease in serum glucose (with an inadequate increase of insulin levels), cholesterol and protein concentrations, elevated transaminases, tubular proteinuria and a low level of antithrombin III (Niehues et al., 1998).

\section{PMM2-CDG (CDG-la): deficiency of phosphomannomutase II (EC 5.4.2.8)}

Phosphomannomutase II occurs in the cytoplasm and catalyzes the conversion of mannose-6-phosphate (Man-6-P) to the mannose-1-phosphate (Man-1-P), which is a precursor required for the synthesis of GDPmannose (GDP-Man) and dolichol-P-mannose (Dol-PMan) (Fig. 1a) (Carchon et al., 1999). Both donors are substrates for the mannosyltransferases involved in the synthesis of lipid-linked oligosaccharide (LLO) precursor. The level of these donors is decreased in CDG patients. PMM2-CDG results from mutations in the PMM2 gene, which codes for a phosphomannomutase (tab.1). Over 90 mutations of this gene have been identified, with R141H and F119L being the most commonly identified, particularly in Northern Europe. In Denmark, about 1 in 60 people, and about 1 in 79 Dutch/Flemish people are carriers of one copy of the $\mathrm{R} 141 \mathrm{H}$ mutation. The F119L mutation probably originates near Denmark, 


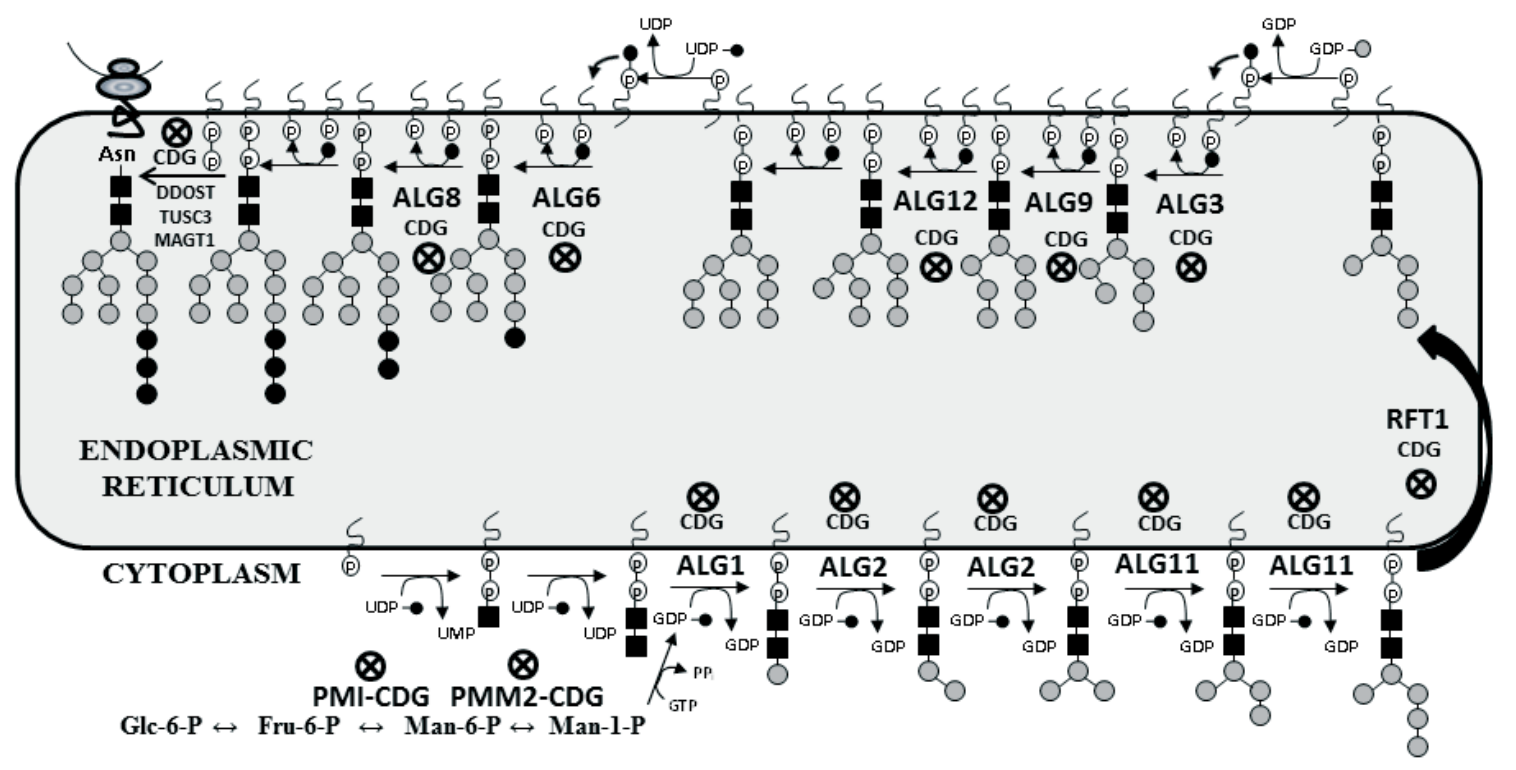

Q Congenital disorder of glycosylation

N-Acetylglucosamine
Mannose
Glucose

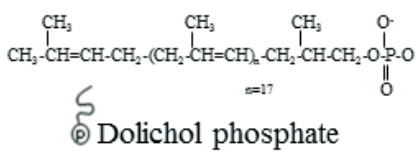

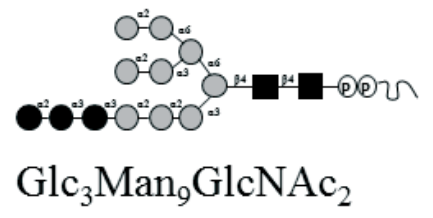

Figure 1a. Location of defects in the N-glycosylation pathway in CDG disorders.

CDG, congenital disorders of glycosylation; Fru, fructose; GDP, guanosine diphosphate; Glc, glucose; Man, mannose; GTP, guanosine triphosphate; PMI, phosphomannose-isomerase; PMM2, phosphomannomutase II; UDP, uridine diphosphate; UMP, uridine monophosphate

where it is present in nearly half of patients with this disorder (Jaeken \& Matthijs, 2001). These mutations lead to the deficiency or instability of phosphomannomutase II (Matthijs et al., 1997; Matthijs et al., 2000). It has been shown that the activity of this enzyme is significantly diminished in fibroblasts, liver cells, and leukocytes, which in turn decreases the pool of GDP-Man and Dol-PMan (van Schaftingen \& Jaeken, 1995). For example, the GDP-Man pool in PMM2-CDG fibroblasts is reduced to $10 \%$ that of normal cells (Freeze \& Westphal, 2001). Fibroblasts of patients with this defect predominantly synthesize incomplete oligosaccharides (truncated forms) containing four or five mannose residues, instead of nine. Impairment of protein $\mathrm{N}$-glycosylation causes simultaneous occurrence in the serum the glycoproteins with normal structure as well as those in which the oligosaccharide part is deficient in sialic acid, galactose and $\mathrm{N}$-acetylglucosamine. It also concerns membranous glycoproteins and lysosomal enzymes (Jaeken \& Stibler, 1989). Often, patients are diagnosed as having the disorder, in their neonatal or early infantile period, on the basis of typical clinical presentation (Jaeken, 2010). A classical phenotype of this disease includes the following symptoms: psychomotor retardation, ataxia, strabismus, some dysmorphic features (inverted nipples and subcutaneous fat pads), and coagulopathy. Most children suffer from epilepsy and some from stroke-like episodes. Some patients have a very mild phenotype. It has been shown that the highest mortality occurs in the first years of life and is caused by malfunctions of many organs and systems (digestive tract, circulatory system, kidneys, liver) (Jaeken, 2010). Approximately 20\% of newborns do not live past their first year of life. Mannose therapy is ineffective (Freeze \& Westphal, 2001).

PMM2-CDG was first described in 1980 by Jaeken et al. (Jaeken et al., 1980) in twin sisters (as the Jaeken syndrome). It was the first-discovered genetic multisystem disorder characterized by defective glycosylation glycoconjugates, but during the next 15 years the underlying defect remained unknown. Only in 1995, it has been shown that this defect was caused by a deficiency of the phosphomannomutase enzyme. PMM2-CDG was the first form of CDG characterized at the molecular level (van Schaftingen \& Jaeken, 1995; Carchon et al., 1999; Freeze \& Westphal, 2001; Grunewald et al., 2002; Marquardt \& Denecke, 2003). This defect is the most frequent type of CDG ( $70 \%$ of all CDG syndromes), with more than 700 cases identified worldwide (Carchon et al., 1999; Freeze \& Westphal, 2001). This disorder occurs in people of many parts of the world (Northern and Western Europe, USA, Latin America, Iran, Japan), but almost half of patients are inhabitants of Scandinavia (Kjaergaard, 2004).

For the diagnosis of PMM2-CDG (and of congenital disorders of N-glycosylation in general), the assessment of the serum transferrin isoform profile by the isoelectrofocusing method (IEF) is widely used. In this defect, the cathodal shift was shown, because of partial deficiency of sialic acid. Therefore, the transferrin isoform pattern presents an increase of both, asialo- and disialo-, and a decrease of tetrasialotransferrin bands Jaeken, 2010). This is a typical profile for type I CDG and that pattern indicates the defects in the earliest synthetic steps of the $\mathrm{N}$-linked oligosaccharide pathway. Also, the 
Table 1. Genetic defects in the N-glycosylation pathway- related CDG disorders (Freeze \& Schachter, 2009; OMIM, 2013).

\begin{tabular}{|c|c|c|c|c|}
\hline CDG Type & $\begin{array}{l}\text { Number } \\
\text { of reported } \\
\text { cases }\end{array}$ & Gene symbol & Protein name & $\begin{array}{l}\text { Phenotype } \\
\text { OMIM* } \\
\text { number }\end{array}$ \\
\hline PMM2-CDG (CDG-la) & 700 & PMM2 & Phosphomannomutase II & 212065 \\
\hline PM1-CDG (CDG-Ib) & 20 & PMI & Phosphomannose isomerase & 602579 \\
\hline ALG6-CDG (CDG-IC) & 30 & $A L G 6$ & a-1,3-glucosyltransferase I & 603147 \\
\hline ALG3-CDG (CDG-Id) & 6 & $A L G 3$ & a-1,3-mannosyltransferase VI & 601110 \\
\hline ALG12-CDG (CDG-Ig) & 6 & ALG12 & a-1,6-mannosyltransferase VIII & 607143 \\
\hline ALG8-CDG (CDG-Ih) & 5 & $A L G 8$ & a-1,3-glucosyltransferase II & 608104 \\
\hline ALG2-CDG (CDG-li) & 1 & $A L G 2$ & a-1,3-mannosyltransferase II & 607906 \\
\hline DPAGT1-CDG (CDG-lj) & 2 & DPAGT1 & $\mathrm{N}$-acetylglucosaminyltransferase I & 608093 \\
\hline ALG1-CDG (CDG-Ik) & 8 & $A L G 1$ & $\beta$-1,4-mannosyltransferase I & 608540 \\
\hline ALG9-CDG (CDG-II) & 2 & ALG9 & a-1,2-mannosyltransferases VII/IX & 608776 \\
\hline RFT1-CDG (CDG-In) & 6 & RFT1 & Flippase & 612015 \\
\hline ALG11-CDG (CDG-Ip) & 5 & $A L G 11$ & a-1,2-mannosyltransferases IV/V & 613661 \\
\hline DDOST-CDG (CDG-Ir) & 1 & DDOST & oligosaccharyltransferase complex & 614507 \\
\hline TUSC3-CDG & 5 & TUSC3 & Subunit TUSC3 of oligosaccharyltransferase complex & 611093 \\
\hline MAGT1-CDG & 4 & MAGT1 & Subunit MAGT1 of oligosaccharyltransferase complex & 300716 \\
\hline MGAT2-CDG (CDG-Ila) & 4 & MGAT2 & $\beta-1,2-N$-acetylglucosaminylo-transferase II & 212066 \\
\hline GCS1-CDG (CDG-IIb) & 1 & GCS1 & a-1,2-glucosidase I & 606056 \\
\hline
\end{tabular}

*OMIM, Online Mendelian Inheritance in Man (updated 1 March 2013).

IEF of serum transferrin can be normal in patients with PMM2-CDG (Fletcher et al., 2000). Additionally, other laboratory tests showed an increase in serum transaminases, hypoalbuminemia, hypocholesterolemia, and tubular proteinuria. Finally, the diagnosis is confirmed by finding a diminished activity of enzyme phosphomannomutase in leukocytes or fibroblasts (van Schaftingen \& Jaeken, 1995).

\section{DPAGT1-CDG (CDG-Ij): deficiency of $\mathrm{N}$-acetylglucosaminyltransferase I (EC 2.7.8.15)}

The biosynthesis of fourteen-sugar lipid linked oligosaccharide (LLO) precursor begins on the cytoplasmic side of the ER membrane with the transfer of $\mathrm{N}$-acetylglucosamine residue from an active donor - UDP-GlcNAc - to membrane-bound lipid-like precursor dolichol phosphate (Dol-P) to create dolichol pyrophosphate N-acetylglucosamine (GlcNAc-PP-Dol) (Freeze \& Schachter, 2009). This process is catalyzed by the N-acetylglucosaminyltransferase I enzyme (Fig. 1a). CDG-Ij is caused by a deficiency in N-acetylglucosaminyltransferase I activity encoded by the DPAGT1 gene (Table 1) (Wu et al., 2003). A few mutations were found in this gene (OMIM, 2013).

The genetic defect DPAGT1-CDG was first described in 2003 in a female patient (Wu et al., 2003), and in 2012 in a male patient (Timal et al., 2012). The first patient showed severe psychomotor retardation, hypotonia, seizures, dysmorphy, exotropia, and microcephaly (Wu et al., 2003), while the second patient had multisystem problems and died at the age of 2.5 (Timal et al., 2012).
An abnormal transferrin isoforms profile was consistent with CDG type I and a significant decrease in activity of $\mathrm{N}$-acetylglucosaminyltransferase I was observed (Wu et al., 2003).

\section{ALG1-CDG (CDG-Ik): deficiency of $\beta-1,4-$ mannosyltransferase I (EC 2.4.1.142)}

Following the attachment of two N-acetylglucosamine residues to membrane-bound dolichol phosphate (Dol-P), the dolichol-linked oligosaccharide chain is further extended in a step-by-step mannosylation process (attachment of nine mannose residues) (Freeze \& Schachter, 2009). The elongation of this chain begins on the cytoplasmic side of ER membrane by the addition of five mannose and ends on the luminal side of this membrane by the attachment of next four mannose residues. The first elongation step is catalyzed by a $\beta-1,4-$ mannosyltransferase I that transfers the first-mannose (of nine which are in the full-sized LLO glycan) from GDP-Man onto the two-sugar LLO precursor - GlcNAc 2 -PP-Dol (Fig.1a). CDG-Ik is caused by a deficiency in $\beta$-1,4-mannosyltransferase $I$ activity encoded by the ALG1 gene (tab.1). A few mutations were identified in this gene (Dupre et al., 2010).

Genetic defect ALG1-CDG was first described in 2004 (Grubenmann et al., 2004). Until now, only 8 patients have been diagnosed (OMIM, 2013). These patients presented severe psychomotor retardation with muscular hypotonia, seizures, microcephaly, and nephrotic syndrome leading to early death (Dupre et al., 2010). Laboratory studies showed a typical pattern of 
transferrin isoforms for CDG type I, an accumulation of GlcNAc - PP-Dol and a significant decrease in the activity of $\beta-1,4-$ mannosyltransferase $\mathrm{I}$ in skin fibroblasts (Dupre et al., 2010).

\section{ALG2-CDG (CDG-li): deficiency of a-1,3- mannosyltransferase II (EC 2.4.1.132)}

On the cytoplasmic side of the ER, three separate mannosyltransferases catalyze the sequential transfer of mannoses from GDP-Man onto the LLO intermediate precursors (Fig. 1a) (Freeze \& Schachter, 2009). Thus, $\alpha-1,3-$ mannosyltransferase attaches the second mannose (of nine) residue to the one-mannose (three-sugar) LLO precursor - ManGlcNAc 2 -PP-Dol (Thiel et al., 2003). It should be noted that all previously known defects in the biosynthesis of LLOs concerned the impaired activity of glycosyltransferases acting at the luminal side of the ER, but this defect was observed at the cytosolic side of the ER. That defect is associated with mutations in the ALG2 gene, which leads to the deficiency of $\alpha-1,3-$ mannosyltransferase (Table 1) (Thiel et al., 2003). As a result, a lack of the two-mannose LLO intermediate precursor - $\mathrm{Man}_{2} \mathrm{GlcNAc}_{2}$-PP-Dol is identified.

The genetic defect ALG2-CDG was first described in 2003 in a female patient (Thiel et al., 2003) and up until now no new cases were diagnosed. This patient showed a severe psychomotor retardation with hypomyelination, seizures, bilateral colobomas of the iris, and hepatomegaly. The laboratory findings show a typical pattern of transferrin isoforms for CDG type I, an accumulation of ManGlcNAc - PP-Dol, a significant decrease in the activity of $\alpha-1,3-$ mannosyltransferase II, and diminished level of coagulation factors (Thiel et al., 2003).

\section{ALG11-CDG (CDG-Ip): deficiency of $a-1,2-$ mannosyltransferases IV/V (EC 2.4.1.131/EC 2.4.1.131)}

On the cytoplasmic side of the ER membrane, $\alpha-1,2$ mannosyltransferases IV/V add fourth and fifth-mannose (of nine) residue from GDP-Man onto the threemannose and four-mannose LLO precursors (Man ${ }_{3}$ Glc$\mathrm{NAc}_{2}$-PP-Dol and $\mathrm{Man}_{4} \mathrm{GlcNAc}_{2}$-PP-Dol, respectively), creating four- and five-mannose intermediate precursors $\left(\mathrm{Man}_{4} \mathrm{GlcNAc}_{2}\right.$-PP-Dol and $\mathrm{Man}_{5} \mathrm{GlcNAc}_{2}$-PP-Dol, respectively) (Fig.1a) (Freeze \& Schachter, 2009). This disorder results from mutations in the ALG11 gene, leading to the deficiency of $\alpha-1,2$-mannosyltransferases IV $/ \mathrm{V}$ (Table 1) (Rind et al., 2010). The deficit of the enzyme leads to the accumulation of incomplete glucosylated LLO precursors (with three or four mannose residues, instead of four or of five, respectively).

The genetic defect ALG11-CDG was first described in 2010 in two siblings, born of consanguineous Turkish parents (Rind et al., 2010). They showed feeding problems, hypotonia, epilepsy, and bilateral deafness. The girl presented severe psychomotor retardation, facial dysmorphism, and died at the age of 2. In 2012, another 3 unrelated patients have been diagnosed (Thiel et al., 2012). Biochemical analysis of serum transferrin isoforms showed a CDG type I pattern (Rind et al., 2010). The typical feature of this disease is the accumulation of shortened LLO intermediate precursors - $\mathrm{Man}_{3}$ Glc$\mathrm{NAc}_{2}$-PP-Dol and $\mathrm{Man}_{4} \mathrm{GlcNAc}_{2}$-PP-Dol in fibroblasts (Jaeken, 2011).

\section{RFT1-CDG (CDG-In): deficiency of flippase}

Flippase translocates the seven-sugar LLO precursor $\left(\mathrm{Man}_{5} \mathrm{GlcNAc}_{2}\right.$-PP-Dol) across the ER membrane towards the luminal side (Fig. 1a) (Freeze \& Schachter, 2009). This disease results from mutations in the RFT1 gene leading to the deficiency of this enzyme and an accumulation of the above mentioned precursor (Table .1) (Haeuptle et al., 2008).

The genetic defect RFT1-CDG was first identified in 2008 (Haeuptle et al., 2008). Six patients from six families have been diagnosed so far (Jaeken, 2010). All these patients showed a severe neurological syndrome including deafness as a consistent feature of this defect. Besides, they had marked developmental retardation, hypotonia, epilepsy, poor to absent visual contact, feeding problems, microcephaly, and dysmorphic features (Jaeken, 2011). The accumulation of LLO intermediate precursor $\left(\mathrm{Man}_{5} \mathrm{GlcNAc}_{2}-\mathrm{PP}-\mathrm{Dol}\right)$ and a strong reduction of complete LLO were observed in fibroblasts (Haeuptle et al., 2008). RFT1-CDG can be detected by capillary zone electrophoresis that showed a pattern of serum transferrin isoforms characteristic for CDG type I Jaeken et al., 2009).

\section{ALG3-CDG (CDG-Id): deficiency of a-1,3- mannosylotransferase VI (EC 2.4.1.258)}

On the ER lumen, specific mannosyltransferases (from VI to IX) catalyze the sequential attachment of the four-mannose residues to the LLO precursor (Man${ }_{5}$ GlcNAc $_{2}$-PP-Dol) (Freeze \& Schachter, 2009). Finally, the nine-mannose (eleven-sugar) structure is formed $\left(\mathrm{Man}_{9} \mathrm{GlcNAc}_{2}\right.$-PP-Dol). $\quad \alpha-1,3$-mannosyltransferase VI catalyzes the attachment of the sixth-mannose (of nine) from Dol-P-Man onto the five-mannose LLO precursor $\left(\mathrm{Man}_{5} \mathrm{GlcNAc}_{2}\right.$-PP-Dol), generating six-mannose intermediate precursor (Fig.1a) (Freeze \& Schachter, 2009). This defect arises due to mutations in the ALG3 gene, which leads to the deficiency of $\alpha-1,3$-mannosyltransferase VI (Table 1) (Korner et al., 1999). The deficiency of this enzyme leads to the truncation of the oligosaccharide chain containing five mannose residues, instead of nine. The five-mannose intermediate precursor is a poor substrate for the oligosaccharyltransferase (OST) complex (because this enzyme prefers full-sized LLO glycans), making it difficult to move to the growing chain of protein. This incomplete and immature precursor begins to accumulate in the cell. It is known that many deficiencies in LLO synthesis produce incomplete intermediates. Therefore, the hypoglycosylation of multiple proteins occurs in this defect, in which glycoproteins are partially or completely devoid of N-glycans (Korner et al., 1999).

Some clinical symptoms with suspicion of a new subtype of CDG were first described in 1995, in a German boy (Stibler et al., 1995), but biochemical and molecular diagnosis and the confirmation of this defect were given later, in 1999 (Korner et al., 1999). Up till now, only six patients have been diagnosed (Rimella-Le-Huu et al., 2008). Patients show severe psychomotor retardation, microcephaly, coloboma of the iris, atrophy of the optic nerve, as well as brain and corpus callosum (Freeze \& Schachter, 2009). The hallmark biochemical feature of this defect is the accumulation of the truncated, incomplete LLO precursor - $\mathrm{Man}_{5} \mathrm{GlcNAc}_{2}$-PP-Dol - in fibroblasts (Kranz et al., 2007). Plasma glycoproteins are markedly hypoglycosylated and the IEF pattern of serum transferrin reveals an additional band at the position of disialotransferrin (Denecke et al., 2005). The asialotransferrin is not detectable. SDS/PAGE method indicates the lack of at least one of the two complete oligosaccharides normally attached to transferrin (Denecke et al., 2005). 
ALG9-CDG (CDG-II): deficiency of $a-1,2-$ mannosyltransferases VII/IX (EC 2.4.1.259/EC 2.4.1.261)

$\alpha-1,2-M a n n o s y l t r a n s f e r a s e s \mathrm{VII} / \mathrm{IX}$, on the ER lumen, catalyze the attachment of the seventh and ninth-mannose (of nine) from Dol-P-Man onto the six-mannose and eight-mannose LLO precursors (Man ${ }_{6} \mathrm{GlCNAc}_{2}-$ PP-Dol and $\mathrm{Man}_{8} \mathrm{GlcNAc}_{2}$-PP-Dol, respectively), forming seven and nine-mannose intermediate precursors $\left(\mathrm{Man}_{7} \mathrm{GlcNAc}_{2}\right.$-PP-Dol and $\mathrm{Man}_{9} \mathrm{GlcNAc}_{2}$-PP-Dol, respectively) (Fig. 1a) (Freeze \& Schachter, 2009). Mutations in ALG9 gene that leads to the deficit of $\alpha-1,2-$ mannosyltransferases VII/IX (Table 1) (Frank et al., 2004) are known to causes this disease. Deficiencies of these enzymes lead to the accumulation of incomplete glucosylated and immature LLO precursors (with six or eight mannose residues, instead of seven or of eight, respectively).

Genetic defect ALG12-CDG was first described in 2004 (Frank et al., 2004). Until now, only 2 patients are known. Patients have mild psychomotor retardation, seizures, muscular hypotonia, diffuse brain atrophy with delayed myelination, severe macrocephaly, and hepatomegaly (Frank et al., 2004). In laboratory studies, an abnormal transferrin isoform profile has been found, typical for CDG type I pattern, with elevated disialo- and asialotransferrin, and dual accumulation of $\mathrm{Man}_{6}$ Glc$\mathrm{NAc}_{2}$-PP-Dol and $\mathrm{Man}_{8} \mathrm{GlcNAc}_{2}$-PP-Dol (Frank et al., 2004; Weinstein et al., 2005).

\section{ALG12-CDG (CDG-Ig): deficiency of a-1,6- mannosyltransferase VIII (EC 2.4.1.260)}

On the luminal side of the ER membrane, $\alpha-1,6-$ mannosyltransferase VIII catalyzes the attachment of the eighth-mannose (of nine) from Dol-P-Man onto the seven-mannose LLO precursor $\left(\mathrm{Man}_{7} \mathrm{GlcNAc}_{2}-\mathrm{PP}-\mathrm{Dol}\right)$, creating eighth-mannose intermediate precursor (Man${ }_{8}$ GlcNAc $_{2}$-PP-Dol) (Fig. 1a) (Freeze \& Schachter, 2009). This defect results from mutations in ALG12 gene and leads to the deficiency of $\alpha-1,6$-mannosyltransferase VIII (Table 1) (Grubenmann et al., 2002). In turn, enzyme deficit leads to the accumulation of incomplete glucosylated LLO precursor (with seven mannose residues instead of 8$)$.

Genetic defect ALG12-CDG was first reported in 2002, in a girl born of nonconsanguineous parents (Chantret et al., 2002; Grubenmann et al., 2002). Only 6 patients have been recognized so far (Jaeken, 2010). Patients present moderate to severe psychomotor retardation, muscular hypotonia, facial dysmorphism, progressive microcephaly, seizures, and frequent upper respiratory tract infections (Chantret et al., 2002; Grubenmann et al., 2002). Biochemical studies showed decreased serum immunoglobulin levels $(\mathrm{IgG})$ and diminished coagulation factors (Chantret et al., 2002; Grubenmann et al., 2002). Serum transferrin isoform pattern was consistent with CDG type I (Grubenmann et al., 2002). Structural analysis of LLO presents an accumulation of intermediate precursor in fibroblasts - $\mathrm{Man}_{7} \mathrm{GlcNAc}_{2}-\mathrm{PP}-\mathrm{Dol}-$ (typical biochemical feature of this defect). The activity of $\alpha-1,6$-mannosyltransferase VIII was significantly reduced in skin fibroblasts (Grubenmann et al., 2002).

\section{ALG6-CDG (CDG-Ic): deficiency of $a-1,3-$ glucosyltransferase I (EC 2.4.1.267)}

Following the mannosylation process the dolichollinked oligosaccharide chain is further extended in a step-by-step glucosylation process to generate a ma- ture, full-sized LLO glycan (fourteen sugars) (Freeze \& Schachter, 2009). $\alpha-1,3$-glucosyltransferase I catalyzes the transfer of the first glucose residue (out of three) from dolichol-P-glucose (Dol-P-Glc) onto the elevensugar LLO precursor $\left(\mathrm{Man}_{9} \mathrm{GlcNAc}_{2}-\mathrm{PP}-\mathrm{Dol}\right)$ forming the twelve-sugar LLO precursor $\left(\mathrm{GlcMan}_{9} \mathrm{GlcNAc}_{2}-\mathrm{PP}-\right.$ Dol) (Fig. 1a) (Freeze \& Schachter, 2009). ALG6-CDG is caused by mutations in the ALG6 gene which leads to the deficiency of $\alpha-1,3$-glucosyltransferase I (tab.1) (Burda et al., 1998; Imbach et al., 1999). In turn, it causes the accumulation of the nonglucosylated LLO intermediate precursor $\left(\mathrm{Man}_{9} \mathrm{GlcNAc}_{2}-\mathrm{PP}-\mathrm{Dol}\right)$ in fibroblasts, which is weakly transmitted to the polypeptide protein chain (Al-Owain et al., 2010).

Genetic defect ALG6-CDG was first described in 1980 in four children from two families (Burda et al., 1998; Korner et al., 1998). This is the second most frequent protein $\mathrm{N}$-glycosylation disorder, and until now 30 patients have been diagnosed (Jaeken, 2010). Patients reveal moderate psychomotor retardation (compared to patients with PMM2-CDG), muscular hypotonia, strabismus, and seizures (Chantret et al., 2003). The biochemical phenotype was characterized by an accumulation of nonglucosylated LLOs precursors, a marked reduction of glucosylated LLOs, incomplete utilization of N-glycosylation sites in nascent glycoproteins, and hypoglucosylation of serum proteins (Burda et al., 1998; Korner et al., 1998). The analysis of serum transferrin isoforms pattern by IEF reveals the CDG type I, in which disialo- and tetrasialotransferrin are the most abundant glycoforms, but asialotransferrin occurs in low amounts (Burda et al., 1998). Laboratory tests indicate low blood levels of factor XI, coagulation inhibitors, and protein C (Jaeken, 2010).

\section{ALG8-CDG (CDG-Ih): deficiency of $a-1,3-$ glucosyltransferase II (EC 2.4.1.265)}

$\alpha-1,3-$ Glucosyltransferase II transfers the second (out of three) glucose residue from dolichol-P-glucose (DolP-Glc) onto the twelve-sugar LLO precursor (Glc$\mathrm{Man}_{9} \mathrm{GlcNAc}_{2}$-PP-Dol), creating the thirteen-sugar LLO precursor $\left(\mathrm{Glc}_{2} \mathrm{Man}_{9} \mathrm{GlcNAc}_{2}\right.$-PP-Dol) (Fig. 1a) (Freeze \& Schachter, 2009). Genetic defect ALG8-CDG (CDGIh) is linked with mutations in the $A L G 8$ gene, that leads to the deficiency of $\alpha-1,3$-glucosyltransferase II (Table 1) (Chantret et al., 2003). Deficit of this enzyme causes accumulation of incomplete glucosylated precursor $\left(\mathrm{GlcMan}_{9} \mathrm{GlcNAc}_{2}\right.$-PP-Dol) and lack of the LLO intermediate precursor $\left(\mathrm{Glc}_{2} \mathrm{Man}_{9} \mathrm{GlcNAc}_{2}\right.$-PP-Dol).

Genetic defect ALG8-CDG was first described in 2003 (Chantret et al., 2003). Until now, only 5 patients from four families have been recognized (Jaeken, 2010). One patient showed normal psychomotor development and had no dysmorphic manifestations, but had severe diarrhea and moderate hepatomegaly (OMIM, 2013). The following clinical symptoms were observed in other patients: dysmorphy, edema, massive ascites, and renal failure (Chantret et al., 2003). The accumulation of incomplete LLO intermediate precursor - GlcMan $_{9}$ GlcNAc $_{2}$-PP-Dol — in fibroblasts constitutes a typical feature of this disease (Schollen et al., 2004). The combination of coagulation factor anomalies and protein-losing enteropathy suggests CDG. Laboratory findings diagnose anemia, severe thrombocytopenia, and primary hypothyroidism (Chantret et al., 2003). Routine hematological tests showed that factor $\mathrm{X}$, protein $\mathrm{C}$, and antithrombin III were decreased (Chantret et al., 2003). The transfer- 
rin isoform profile is presented as a typical pattern for CDG type I.

\section{DDOST-CDG (CDG-Ir): deficiency of} oligosaccharyltransferase complex (OST) (EC 2.4.99.18)

The oligosaccharyltransferase complex (OST) en bloc transfers the membrane-anchored dolichol-liniked fourteen-sugar $\mathrm{Glc}_{3} \mathrm{Man}_{9} \mathrm{GlcNAc}_{2}$ glycan to a growing polypeptide chain of nascent protein by cleavage of the GlcNAc-P bond and release of dolichol diphosphate (Dol-PP) (Fig. 1a) (Freeze \& Schachter, 2009). This disease results from mutations in the DDOST gene, leading to the deficiency of this enzyme (Table 1) (Jones et al., 2012).

Genetic defect DDOST-CDG was described in 2012, in a 6-month-old boy of European descent (Jones et al., 2012). He showed hypotonia, external strabismus, mild to moderate liver dysfunction, delayed psychomotor development with walking, and never developed speech. The transferrin isoform profile showed a typical for CDG type I pattern, in which both, mono- and aglycosylated transferrins were markedly increased. Laboratory studies revealed a deficiency of coagulation factor XI, antithrombin III, protein C, and protein S (Jones et al., 2012).

\section{TUSC3-CDG: deficiency of subunit TUSC3 of oligosaccharyltransferase complex (EC 2.4.99.18)}

The human oligosaccharyltransferase complex contains 7 subunits (Mohorko et al., 2011). One of them is TUSC3 or IAP (MAGT1). These two are paralogous and mutually exclusive subunits of this enzyme (Fig. 1a).
These subunits are proposed to display oxidoreductase activity. This disorder results from mutations in the TUSC3 gene (Table 1) (Garshasbi et al., 2011).

Genetic defect TUSC3-CDG was first described in 2008, in two families (Iranian and French) (Molinari et al., 2008; Garshasbi et al., 2011). Five patients have been recognized so far, in which nonsyndromic moderate mental retardation was observed. The transferrin isoform profile showed a normal pattern (Garshasbi et al., 2008).

\section{MAGT1-CDG: deficiency of subunit MAGT1 of} oligosaccharyltransferase complex (EC 2.4.99.18)

The deficiency of subunit MAGT1 of the oligosaccharyltransferase complex of second paralog, is caused by mutations in the LAP gene (Fig. 1a) (Table 1) (Molinari et al., 2008).

Genetic defect MAGT1-CDG was first described in 2008, in an Australian family, and presented nonsyndromic X-linked mental retardation (Molinari et al., 2008). Two girls had mild mental retardation, and two boys severe mental retardation. Glycosylation analyses of patients' fibroblasts showed normal N-glycan synthesis and transfer, suggesting that normal N-glycosylation observed in patients fibroblasts may be observed due to functional compensation (Molinari et al., 2008). The transferrin isoform profile by IEF method was not performed (Molinari et al., 2008).

\section{GCS1-CDG (CDG-Illb): deficiency a-1,2-glucosidase I (EC 3.2.1.106)}

The fourteen-sugar $\mathrm{Glc}_{3} \mathrm{Man}_{9} \mathrm{GlcNAc}_{2}$ glycan, after being attached to the protein, undergoes further modi-

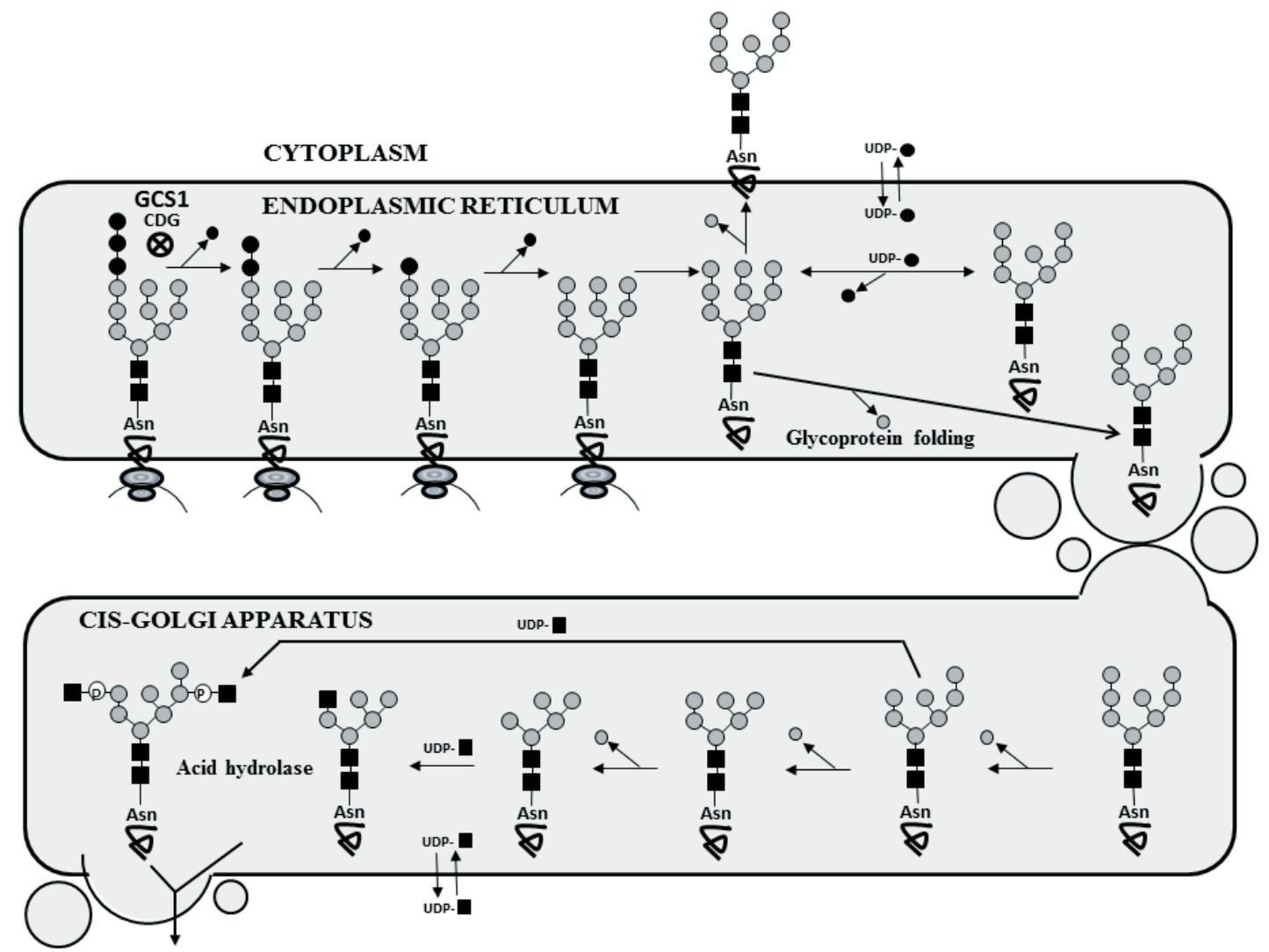

Figure $1 \mathrm{~b}$. Processing and maturation of an $\mathrm{N}$-glycan in the endoplasmic reticulum and cis-Golgi apparatus. Asn, asparagine; UDP, uridine diphosphate 
fication by a series of trimming/processing reactions to the forming multiantennary complex-type glycans (Freeze \& Schachter, 2009). Trimming of the oligosaccharide chain begins with the sequential removal of three glucose and one mannose residues creating ten-sugar chain $\left(\mathrm{Man}_{8} \mathrm{GlcNAc}_{2}\right)$, which leaves the ER and passes to the Golgi apparatus. On the ER lumen, $\alpha$-1,2-glucosidase I removes the first terminal $\alpha 1,2$-linked glucose (Fig. 1b). This disturbance results from mutations in the GCS1 (Table 1) (de Praeter et al., 2000). $\alpha$-1,2-glucosidase I deficiency causes an increase in the activity of the pathway involving endo $\alpha-1,2$-mannosidase that cuts off the foursugar structure ( $\left.\mathrm{Glc}_{3} \mathrm{Man}\right)$ from the oligosaccharide chain (Volker et al., 2002). The remaining part of the chain can be further extended.

Genetic defect GCS1-CDG was first identified in 2000, in a female neonate (de Praeter et al., 2000). Only one case has been described so far. The patient displayed generalized hypotonia, dysmorphic features, hepatomegaly, hypoventilation, feeding problems, seizures, and fatal outcome at the age of 74 days (de Praeter et al., 2000). In laboratory studies, a normal profile of serum transferrin isoforms, accumulation of abnormal tetrasaccharide ( $\left.\mathrm{Glc}_{3} \mathrm{Man}\right)$ in urine, and severe reduced of $\alpha-1,2-$ glucosidase I activity in the liver tissue and cultured skin fibroblasts have been shown (de Praeter et al., 2000).

\section{MGAT2-CDG (CDG-Ila): deficiency of $\beta-1,2-\mathrm{N}$ - acetylglucosaminyltransferase II (EC 2.4.1.143)}

For most glycoproteins (mature membrane and secreted glycoproteins), three mannose residues are removed and the first (out of two) $\mathrm{N}$-acetylglucosamine residue is added to the chain in the cis compartment of the Golgi, forming eight-sugar chain $\left(\right.$ GlcNAcMan $_{5}$ Glc-
$\mathrm{NAc}_{2}$ ). Then, this glycan passes to the medial compartment (Fig. 1b). In this compartment, two outer mannose residues are removed, and the second N-acetylglucosamine as well as fucose residues are attached to the core of $\mathrm{Man}_{3} \mathrm{GlcNAc}_{2}$ (Fig. 1c). This glycan passes to the trans Golgi compartment, where two galactose and two sialic acid residues are added, generating an $\mathrm{N}$ glycan complex with two branches. All N-glycans have a common five-sugar core (two $\mathrm{N}$-acetylglucosamine and three mannose residues) and are classified into the following three types: oligomannose, complex, and hybrid. $\quad \beta-1,2-\mathrm{N}$-acetylglucosaminyltransferase II adds the second $\mathrm{N}$-acetylglucosamine to the $\beta$-linked mannose of biantennary complex-type chains (Freeze \& Schachter, 2009). This disorder results from mutations in the MGAT2 gene causing the deficiency of $\beta-1,2-\mathrm{N}$ acetylglucosaminyltransferase II (Table 1) (Fig. 1c) (Tan et al., 1996).

Genetic defect MGAT2-CDG was first described in 1991 in an Iranian child (Ramaekers et al., 1991). This disorder has been identified only in four patients (OMIM, 2013). These patients had severe psychomotor retrdation, hypotonia, seizures, craniofacial dysmorphy, and gastrointestinal disturbances (Tan et al., 1996). The diagnosis was confirmed by isoelectric focusing of serum transferrin, which showed an abnormal profile, typical for CDG type II pattern (increase of disialo-, and asialo-, trisialo-and/or monosialotransferrin (Jaeken et al., 1994). The activity of $\beta-1,2-\mathrm{N}$-acetylglucosaminyltransferase II, an enzyme localized in the Golgi apparatus, was reduced in fibroblasts (Jaeken et al., 1994). Biochemical differences from classic CDG-Ia are: the absence of proteinuria, no change in serum alanine transaminase activity, normal serum albumin level, deficiency of clotting factors IX

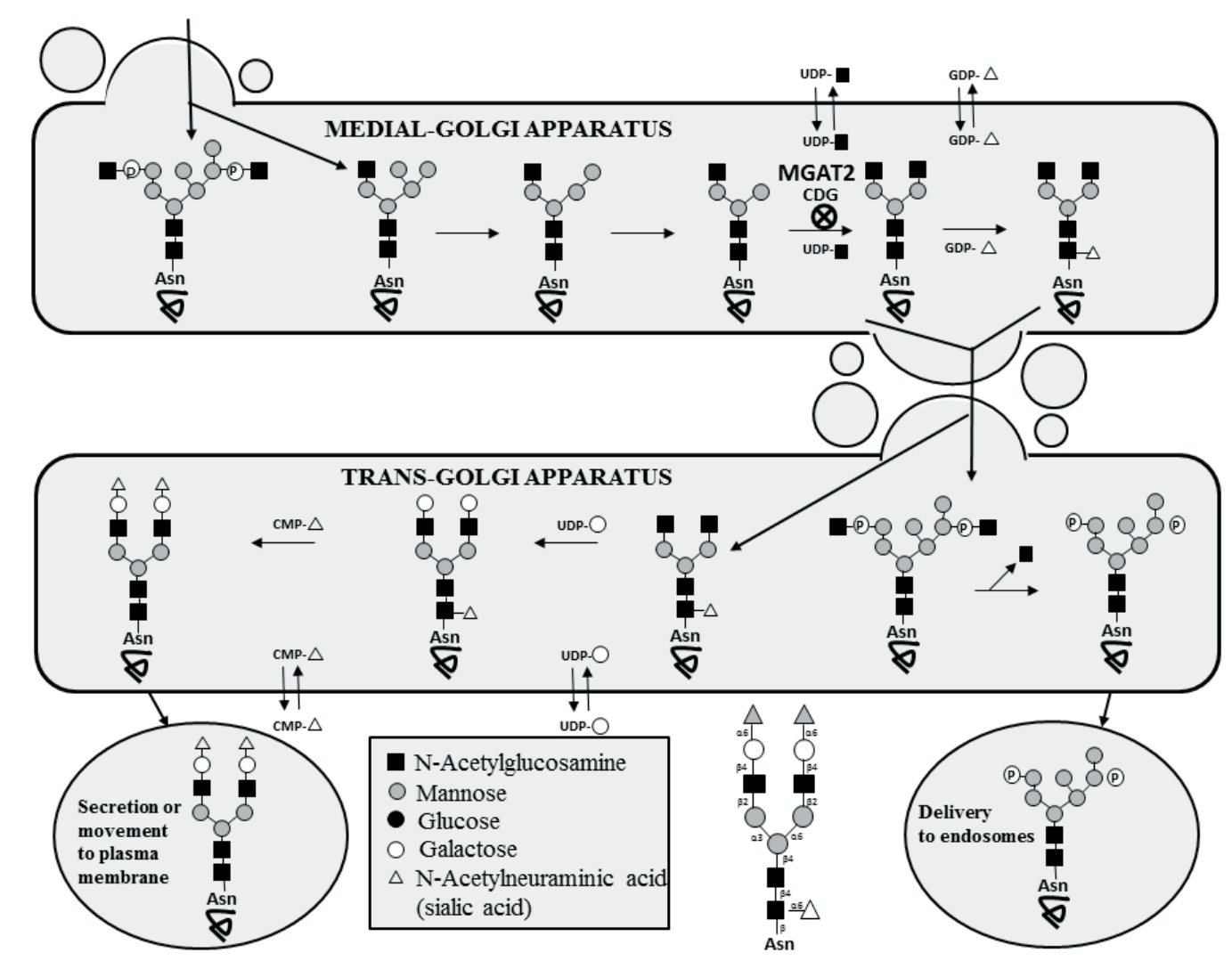

Figure 1c. Processing and maturation of an N-glycan in the medial- and trans-Golgi apparatus.

Asn, asparagine; CMP, cytidine monophosphate; UDP, uridine diphosphate; GDP, guanosine diphosphate 


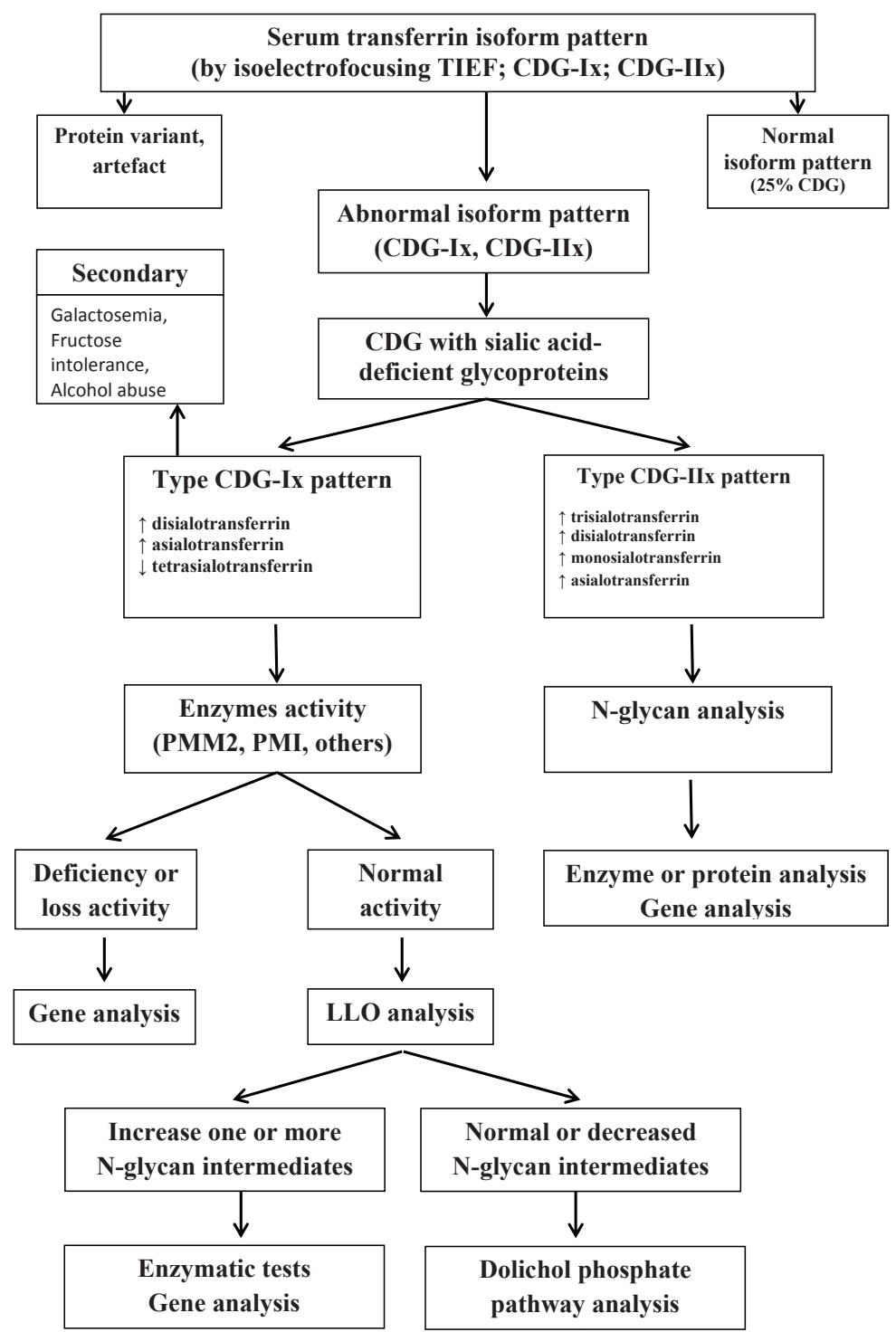

Figure 2. Outline of CDG laboratory diagnostics.

The first step in the laboratory diagnostics of congenital disorders of glycosylation (CDG) is the assessment of serum transferrin isoform pattern by TIEF transferrin isoelectrofocusing (TIEF) method. In case of an abnormal result, an artifact, a transferrin protein variant, and a secondary CDG, should be excluded. There are two types of profiles: the type I pattern points to an assembly defect (in the cytosol or endoplasmic reticulum; CDG-Ix, where $\mathrm{x}$ is the letter of alphabet corresponding to the type of disorder) and type II pattern to a processing defect (in the endoplasmic reticulum or Golgi apparatus; CDG-IIx). In the next step, a detailed diagnostics is performed separately for each type of CDG. In the CDG-Ix diagnosis, measurements of the enzymatic activity of phosphomannomutase II and phosphomannose isomerase in fibroblasts or leukocytes, and lipid-linked oligosaccharides analysis (LLO) in fibroblasts, and a detailed enzymatic analysis and/or mutation analysis are required. If there is no specific abnormal pattern, a defect in the dolichol-phosphate pathway should be considered. In the CDG-Ilx diagnosis, the transferrin N-glycan structure analysis, and detailed enzymatic tests and/or mutation analysis are needed.

and XII, normal activity in serum of arylsulfatase A, and a decreased activity of $\beta$-glucuronidase. Some patients also had an increased serum carbohydrate-deficient transferrin (OMIM, 2013).

\section{LABORATORY DIAGNOSTICS OF CDG}

Laboratory findings for the diagnosis of congenital disorders of glycosylation should be performed as a firstline screening not only in patients with suspected genetic defects, but also in case of any unexplained syndromes. The assessment of the pattern of serum transferrin isoforms by the transferrin isoelectrofocusing method still remains the golden standard for the diagnosis of $\mathrm{CDG}$ (CDG-Ix i CDG-IIx, where $\mathrm{x}$ is the letter correspond- ing to the type of disease), due to $\mathrm{N}$-glycosylation defect (TIEF) (Freeze \& Schachter, 2009). In case of an abnormal result, an artifact, a transferrin protein variant or a secondary CDG (galactosemia, fructose intolerance, alcohol abuse, others) should be excluded. However, not all CDG types can be detected by TIEF. About $25 \%$ of the identified CDG may have a normal profile (Jaeken, 2010). For example, normal transferrin isoform pattern was described in patients with GCS1-CDG (CDG-IIb), SLC35C1-CDG (CDG-IIc) and SLC35A1-CDG (CDGIIf). Patients with PMM2-CDG (CDG-Ia) may also have a normal TIEF profile (Fletcher et al., 2000). It should be mentioned that some of the CDG patients younger than 3 or even 6 months of age may show normal transferrin glycosylation (Morava et al., 2008; Morava et al., 2010; 
Lefeber et al., 2011). Modifications in the glycosylation pattern of serum transferrin occur in patients suffering from CDG where the normal transferrin isoform profile is shifted to the cathode in both type I and type II CDG with hypoglycosylation (Theodore \& Morava, 2011). There is a difference between serum transferrin isoform patterns in type I and type II CDG. The type I profile is characterized by increased disialo- and asialoand decreased tetrasialotransferrin, while in the type II CDG, by an increase of trisialo-, disialo-, monosialo- and asialotransferrin (Theodore \& Morava, 2011).

The next step in the identification of congenital disorders of glycosylation type I (CDG-Ix) is the determination of two enzymes' activity: phosphomannomutase II (PMM2) and phosphomannose isomerase (PMI) in fibroblasts or leukocytes (Jaeken, 2010). If these results are negative, then the identification of lipid linked oligosaccharide precursor (LLO) accumulated in fibroblasts is performed. An increase of one or more N-glycan intermediates, permits to make a preliminary diagnosis that should be confirmed by further enzymatic tests and/or genetic analysis. In turn, if $\mathrm{N}$-glycan intermediates values are normal or decreased, and there is no specific abnormal pattern, a defect in the dolichol-phosphate pathway should be taken into consideration (Jaeken, 2010).

If a type II TIEF pattern is found, the diagnosis of congenital disorders of glycosylation (CDG-IIx) should be further performed using two different analyses: Nglycan structures of serum transferrin, and O-glycan of apolipoprotein C-III by isoelectrofocusing (IEF), to find glycosylation defects of a mucin-type glycan (Jaeken, 2010). The pattern of the transferrin glycan has a specific profile with an accumulation of glycan intermediates in Golgi apparatus only in a small number of cases. In most cases, this pattern is nonspecific with some degree of hyposialylation and/or hypogalactosylation (Jaeken, 2010). Therefore, further diagnostics should include a clinical presentation. If there is still no diagnosis, mutation analysis (gene testing) should be performed. The outline of CDG laboratory diagnostics is presented in Fig. 2.

\section{SUMMARY}

Congenital disorders of glycosylation (CDG) constitute a rapidly growing disease family due to genetic defects in the glycosylation pathway of proteins and lipids. Since the first clinical description in year 1980, 45 CDG have been identified, and a novel nomenclature and classification were developed. This paper reviews CDG due to defects only in the $\mathrm{N}$-glycosylation pathway of proteins, on the basis of current knowledge. In this group, 17 different genetic defects have been recognized. Most of these diseases have been discovered recently and frequently concern a small number of patients. CDG are an important clinical problem due to the fact that they cause severe multiorgan and multisystem disorders manifested as early as in the first months of life and about $20 \%$ of patients do not live past their fifth years of life. The variability of clinical presentation makes it difficult for physicians to diagnose these patients. Regarding that about 250 genes are considered to be involved in glycosylation, it should be expected that many diseases are yet to be identified in the near future. Rapidly developing modern laboratory diagnostics will help with that. Therefore, the cooperation between the physician and the laboratory is of great importance. The purpose of this paper is to draw attention to congenital disorders of glycosylation in cases when the disease is of unknown origin, especially when the patient has a broad spectrum of clinical symptoms andof psychomotor retardation.

\section{REFERENCES}

Al-Owain M, Mohamed S, Kaya N, Zagal A, Matthijs G, Jaeken J (2010) A novel mutation and first report of dilated cardiomyopathy in ALG6-CDG (CDG-Ic): a case report. Orphanet J Rare Dis 16: 5-7.

Burda P, Borsig L, de Rijk-Andel J, Wevers R, Jaeken J, Carchon H, Berger EG, Aebi M (1998) A novel carbohydrate-deficient glycoprotein syndrome characterized by a deficiency in glucosylation of the dolichol-linked oligosaccharide. J Clin Invest 102: 647-652.

Carchon H, van Schaftingen E, Matthijs G, Jaeken J (1999) Carbohydrate-deficient glycoprotein syndrome type $1 \mathrm{~A}$ (phosphomannomutase deficiency). Biochim Biophys Acta 1455: 155-165.

Chantret I, Dancourt J, Dupre T, Delenda C, Bucher S, VuillaumierBarrot S, Ogier de Baulny H, Peletan C, Danos O, Seta N, Durand G, Oriol R, Codogno P, Moore SE (2003) A deficiency in dolichylP-glucose:Glc-1-Man-9-GlcNAc2-PP-dolichyl alpha-3-glucosyltransferase defines a new subtype of congenital disorders of glycosylation. J Biol Chem 278: 9962-9971.

Chantret I, Dupre T, Delenda C, Bucher S, Dancourt J, Barnier A, Charollais A, Heron D, Bader-Meunier B, Danos O, Seta N, Durand G, Oriol R, Codogno P, Moore SE (2002) Congenital disorders of glycosylation type Ig is defined by a deficiency in dolichylP-mannose:Man-7-GlcNAc2-PP-dolichyl mannosyltransferase. J Biol Chem 277: 25815-25822.

De Lonlay P, Seta N (2009) The clinical spectrum of phosphomannose isomerase deficiency, with an evaluation of mannose treatment for CDG-Ib. Biochim Biophys Acta 792: 841-843.

Denecke J, Kranz C, von Kleist-Retzow JCh, Bosse K, Herkenrath P, Debus O, Harms E, Marquardt T (2005) Congenital disorder of glycosylation type Id: clinical phenotype, molecular analysis, prenatal diagnosis, and glycosylation of fetal proteins. Pediatr Res 58: 248-253.

De Praeter CM, Gerwig GJ, Bause E, Nuytinck LK, Vliegenthart JF, Breuer W, Kamerling JP, Espeel MF, Martin JJ, de Paepe AM, Chan NW, Dacremont GA, van Coster RN (2000) A novel disorder caused by defective biosynthesis of N-linked oligosaccharides due to glucosidase I deficiency. Am I Hum Genet 66: 1744-1756.

Dupre T, Vuillaumier-Barrot S, Chantret I, Yayé HS, Le Bizec C, Afenjar A, Altuzarra C, Barnérias C, Burglen L, de Lonlay P, Feillet F, Napuri S, Seta N, Moore SE (2010) Guanosine diphosphatemannose:GlcNAc2-PP-dolichol mannosyltransferase deficiency (congenital disorders of glycosylation type Ik): five new patients and seven novel mutations. J Med Genet 47: 729-735.

Fletcher JM, Matthijs G, Jaeken J, van Schaftingen E, Nelson PV (2010) Carbohydrate-deficient glycoprotein syndrome: beyond the screen. J Inherit Metab Dis 23: 396-398.

Frank CG, Grubenmann CE, Eyaid W, Berger EG, Aebi M, Hennet T (2004) Identification and functional analysis of a defect in the human ALG9 gene: definition of congenital disorder of glycosylation type IL. Am J Hum Genet 75: 146-150.

Freeze HH, Schachter H (2009) Genetic Disorders of Glycosylation. In Essential of Glycobiology. Varki A, Cummings RD, Esko JD, Freeze HH, Stanley P, Bertozzi CR, Hart GW, Etzler ME, 2nd eds, pp 585-600. Cold Spring Harbor Laboratory Press, Cold Spring Harbor, New York.

Freeze HH, Westphal V (2001) Balancing N-glycosylation to avoid disease. Biochimie 83: 791-799.

Garshasbi M, Hadavi V, Habibi H, Kahrizi K, Kariminejad R, Behjati F, Tzschach A, Najmabadi H, Ropers HH, Kuss AW (2008) A defect in the TUSC3 gene is associated with autosomal recessive mental retardation. Am J Hum Genet 82: 1158-1164.

Garshasbi M, Kahriz, K, Hosseini M, Nouri Vahid L, Falah M, Hemmati S, Hu H, Tzschach A, Ropers HH, Najmabadi H, Kuss AW (2011) A novel nonsense mutation in TUSC3 is responsible for non-syndromic autosomal recessive mental retardation in a consanguineous Iranian family. Am J Med Genet 155A: 1976-1980.

Grubenmann CE, Frank CG, Hulsmeier AJ, Schollen E, Matthijs G, Mayatepek E, Berger EG, Aebi M, Hennet T (2004) Deficiency of the first mannosylation step in the $\mathrm{N}$-glycosylation pathway causes congenital disorder of glycosylation type Ik. Hum Molec Genet 13: $535-542$.

Grubenmann CE, Frank CG, Kjaergaard S, Berger EG, Aebi M, Hennet T (2002) ALG12 mannosyltransferase defect in congenital disorder of glycosylation type Ig. Hum Molec Genet 11: 2331-2339.

Grunewald S, Matthijs G, Jaeken J (2002) Congenital disorders of glycosylation: a review. Pediat Res 52: 618-624.

Haeuptle MA, Pujol FM, Neupert C, Winchester B, Kastaniotis AJ, Aebi M, Hennet T (2008) Human RFT1 deficiency leads to a disorder of N-linked glycosylation. Am J Hum Genet 82: 600-606. 
Imbach T, Burda P, Kuhnert P, Wevers RA, Aebi M, Berger EG Hennet $T$ (1999) A mutation in the human ortholog of the Saccharomyces cerevisiae ALG6 gene causes carbohydrate-deficient glycoprotein syndrome type-Ic. Proc Nat Acad Sci 96: 6982-6987.

Jaeken J (2010) Congenital disorders of glycosylation. Ann NY ACAD Sci 1214: 190-198.

Jaeken J (2011) Congenital disorders of glycosylation (CDG): it's (nearly) all in it! I Inherit Metab Dis 34: 853-858.

Jaeken J, Hennet T, Matthijs G, Freeze HH (2009) CDG nomenclature: time for a change! Biochim Biophys Acta 1792: 825-826.

Jaeken J, Matthijs G (2001) Congenital disorders of glycosylation. Annu Rev Genomics Hum Genet 2: 129-151.

Jaeken J, Schatchter H, Carchon H, de Cock P, Coddeville B, Spik G (1994) Carbohydrate-deficient glycoprotein syndrome type II: a deficiency in Golgi localized N-acetyl-glucosaminyltransferase II. Arc Dis Child 71: 123-127.

Jaeken J, Stibler H (1989) A newly recognized inherited neurological disease with carbohydrate deficient secretory glycoproteins. In Genetics of Neuropsychiatric Diseases. Wetterberg L, ed, pp 69-80. WennerGren International Symposium Series, 51, Macmillan Press, London.

Jaeken J, Vanderschueren-Lodeweyckx M, Casaer P, Snoeck L, Corbeel L, Eggermont E, Eeckels R (1980) Familial psychomotor retardation with markedly fluctuating serum prolactin, FSH and GH levels, partial TBG-deficiency, increased serum arylsulphatase $A$ and increased CSF protein: a new syndrome? Pediat Res 14: 179.

Jaeken J, Vleugels W, Régal L, Corchia C, Goemans N, Haeuptle MA, Foulquier F, Hennet T, Matthijs G, Dionisi-Vici C (2009) RFT1CDG: deafness as a novel feature of congenital disorders of glycosylation. I Inherit Metab Dis 32 (Suppl 1): S335-338.

Jones MA, Ng BG, Bhide S, Chin E, Rhodenizer D, He P, Losfeld ME, He M, Raymond K, Berry G, Freeze HH, Hegde MR (2012) DDOST mutations identified by whole-exome sequencing are implicated in congenital disorders of glycosylation. Am J Hum Genet 90: 363-368

Kjaergaard S (2004) Congenital disorders of glycosylation type Ia and Ib. Genetic, biochemical and clinical studies. Dan Med Bull 51: 350363.

Korner C, Knauer R, Holzbach U, Hanefeld F, Lehle L, von Figura $\mathrm{K}$ (1998) Carbohydrate-deficient glycoprotein syndrome type $\mathrm{V}$ : deficiency of dolichyl-P-Glc:Man(9)GlcNAc(2)-PP-dolichyl glucosyltransferase. Proc Nat Acad Sci 95: 13200-13205.

Korner C, Knauer R, Stephani U, Marquardt T, Lehle L, von Figura K (1999) Carbohydrate deficient glycoprotein syndrome type IV: deficiency of dolichyl-P-Man:Man(5)GlcNAc(2)-PP-dolichyl mannosyltransferase. EMBO J 18: 6816-6822.

Kranz C, Sun L, Eklund E A (2007) CDG-Id in two siblings with partially different phenotypes. Am J Med Genet 143A: 1414-1420.

Lefeber DJ, Morava E, Jaeken J (2011) How to find and diagnose a CDG due to defective N-glycosylation. I Inherit Metab Dis 34: 849852 .

Marquardt T, Denecke J (2003) Congenital disorders of glycosylation: review of their molecular bases, clinical presentations and specific therapies. Europ I Pediat 162: 359-379.

Matthijs G, Schollen E, Bjursell C, Erlandson A, Freeze H, Imtiaz F, Kjaergaard S, Martinsson T, Schwartz M, Seta N, VuillaumierBarrot S, Westphal V, Winchester B (2000) Mutation update: mutations in PMM2 cause congenital disorders of glycosylation, type Ia (CDG-Ia). Hum Mutat 16: 386-394.

Matthijs G, Schollen E, Pardon E, Veiga-Da-Cunha M, Jaeken J, Cassiman JJ, Van Schaftingen E (1997) Mutations in PMM2, a phosphomannomutase gene on chromosome 16p13, in carbohydrate-deficient glycoprotein type I syndrome (Jaeken syndrome). Nat Genet 16: 88-92.

Mohorko E, Glockshuber R, Aebi M (2011) Oligosaccharyltransferase: the central enzyme of N-linked protein glycosylation. I Inherit Metab Dis 34: 869-878.

Molinari F, Foulquier F, Tarpey PS, Morelle W, Boissel S, Teague J, Edkins S, Futreal PA, Stratton MR, Turner G, Matthijs G, Gecz J, Munnich A, Colleaux L (2008) Oligosaccharyltransferase-subunit mutations in nonsyndromic mental retardation. Am J Hum Genet 82: 1150-1157.

Morava E, Lefeber DJ, Urban Z, de Meirleir L, Meinecke P, Gillessen Kaesbach G, Sykut-Cegielska J, Adamowicz M, Salafsky I, Ranells J, Lemyre E, van Reeuwijk J, Brunner HG, Wevers RA (2008) Defining the phenotype in an autosomal recessive cutis laxa syndrome with a combined congenital defect of glycosylation. Eur J Hum Genet 16: 28-35.

Morava E, Wevers RA, Cantagrel V, Hoefsloot LH, Al-Gazali L, Schoots J, van Rooij A, Huijben K, van Ravenswaaij-Arts CM, Jongmans MC, Sykut-Cegielska J, Hoffmann GF, Bluemel P, Adamowicz M, van Reeuwijk J, Ng BG, Bergman JE, van Bokhoven H, Korner C, Babovic-Vuksanovic D, Willemsen MA, Gleeson JG,
Lehle L, de Brouwer AP, Lefeber DJ (2010) A novel cerebello-ocular syndrome with abnormal glycosylation due to abnormalities in dolichol metabolism. Brain 133: 3210-3220.

Niehues R, Hasilik M, Alton G, Korner C, Schiebe-Sukumar M, Koch HG, Zimmer KP, Wu R, Harms E, Reiter K, von Figura K, Freeze HH, Harms HK, Marquardt T (1998) Carbohydrate-deficient glycoprotein syndrome type Ib. Phosphomannose isomerase deficiency and mannose therapy. I Clin Invest 101: 1414-1420.

OMIM. Online Mendelian Inheritance in Man. An Online Catalog of $\mathrm{Hu}-$ man Genes and Genetic Disorders. http://www.omim.org/ (updated 1 March 2013).

Participants, "First International Workshop On CDGS", Leuven, Belgium 2000. Carbohydrate-deficient glycoprotein syndromes become congenital disorders of glycosylation: an updated nomenclature for CDG. Glycobiology 10: III-IV.

Pelletier VA, Galeano N, Brochu P, Morin CL, Weber AM, Roy CC (1986) Secretory diarrhea with protein-losing enteropathy, enterocolitis cystica superficialis, intestinal lymphangiectasia, and congenital hepatic fibrosis: a new syndrome. J Pediat 108: 61-65.

Ramaekers VT, Stibler H, Kint J, Jaeken J (1991) A new variant of the carbohydrate deficient glycoproteins syndrome. J Inherit Metab Dis 14: 385-388.

Rimella-Le-Huu A, Henry H, Kern I, Hanquinet S, Roulet-Perez E, Newman CJ, Superti-Furga A, Bonafe L, Ballhausen D (2008) Congenital disorder of glycosylation type Id (CDG Id): phenotypic, biochemical and molecular characterization of a new patient. I Inherit Metab Dis 2 (Suppl): S381-386.

Rind N, Schmeiser V, Thiel C, Absmanner B, Lubbehusen J, Hocks J, Apeshiotis N, Wilichowski E, Lehle L, Korner C (2010) A severe human metabolic disease caused by deficiency of the endoplasmatic mannosyltransferase hALG11 leads to congenital disorder of glycosylation-Ip. Hum Molec Genet 19: 1413-1424.

Schollen E, Frank CG, Keldermans L, Reyntjens R, Grubenmann CE, Clayton PT, Winchester BG, Smeitink J, Wevers RA, Aebi M, Hennet T, Matthijs G (2004) Clinical and molecular features of three patients with congenital disorders of glycosylation type Ih (CDG-Ih) (ALG8 deficiency). (Letter) J Med Genet 41: 550-556.

Sillanaukee P, Ponnio M, Jaaskelainen P (1999) Occurrence of sialic acids in healthy humans and different disorders. Eur J Clin Invest 29: $41-425$.

Stibler H, Stephani U, Kutsch (1995) Carbohydrate-deficient glycoprotein syndrome: a fourth type. Neuropediatrics 26: 235-237.

Tan J, Dunn J, Jaeken J, Schachter H (1996) Mutations in the MGAT2 gene controlling complex N-glycan synthesis cause carbohydratedeficient glycoprotein syndrome type II, an autosomal recessive disease with defective brain development. Am J Hum Genet 59: $810-817$

Theodore M, Morava E (2011) Congenital disorders of glycosylation: sweet news. Cur Opin Pediatr 23: 581-587.

Thiel C, Rind N, Popovici D, Hoffmann GF, Hanson K, Conway RL, Adamski CR, Butler E, Scanlon R, Lambert M, Apeshiotis N, Thiels C, Matthijs G, Korner C (2012) Improved diagnostics lead to identification of three new patients with congenital disorder of glycosylation-Ip. Hum Mutat 33: 485-487.

Thiel C, Schwarz M, Peng J, Grzmil M, Hasilik M, Braulke T, Kohlschutter A, von Figura K, Lehle L, Korner C (2003) A new type of congenital disorders of glycosylation (CDG-Ii) provides new insights into the early steps of dolichol-linked oligosaccharide biosynthesis. I Biol Chem 278: 22498-22505.

Timal S, Hoischen A, Lehle L, Adamowicz M, Huijben K, SykutCegielska J, Paprocka J, Jamroz E, van Spronsen FJ, Korner C, Gilissen C, Rodenburg RJ, Eidhof I, Van den Heuvel L, Thiel C, Wevers RA, Morava E, Veltman J, Lefeber DJ (2012) Gene identification in the congenital disorders of glycosylation type I by wholeexome sequencing. Hum Molec Genet 21: 4151-4161.

Van Schaftingen E, Jaeken J (1995) Phosphomannomutase deficiency is a cause of carbohydrate-deficient glycoprotein syndrome type I. FEBS Lett 377: 318-320.

Volker C, De Praeter CM, Hardt B, Breuer W, Kalz-Fuller B, van Coster RN, Bause E (2002) Processing of N-linked carbohydrate chains in a patient with glucosidase I deficiency (CDG type IIb). Glycobiology 12: 473-483.

Weinstein M, Schollen E, Matthijs G, Neupert C, Hennet T, Grubenmann CE, Frank CG, Aebi M, Clarke JT, Griffiths A, Seargeant L, Poplawski N (2005) CDG-IL: an infant with a novel mutation in the ALG9 gene and additional phenotypic features. Am J Med Genet A 136: 194-197.

Wu X, Rush JS, Karaoglu D, Krasnewich D, Lubinsky MS, Waechter CJ, Gilmore R, Freeze HH (2003) Deficiency of UDPGlcNAc:dolichol phosphate N-acetylglucosamine-1 phosphate transferase (DPAGT1) causes a novel congenital disorder of glycosylation type Ij. Hum Mutat 22: 144-150. 